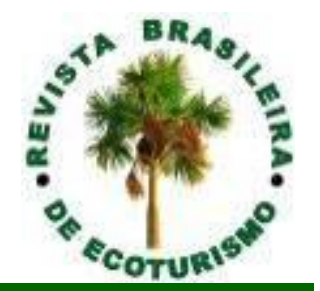

\title{
Turismo Sustentável: alternativa para o desenvolvimento da APA Baia Negra, Pantanal de Mato Grosso do Sul
}

\section{Sustainable Tourism: alternative for the development of the APA Baia Negra, Pantanal of Mato Grosso do Sul (Brazil)}

\author{
Marta Regina da Silva-Melo, Gleidson André Pereira de Melo, \\ Neiva Maria Robaldo Guedes
}

\begin{abstract}
RESUMO: O presente estudo tem como objetivo identificar o potencial da Área de Proteção Ambiental Baía Negra, localizada no município de Ladário, no Pantanal de Mato Grosso do Sul, para a prática do turismo sustentável, como alternativa do desenvolvimento local. O estudo foi conduzido por meio da pesquisa qualitativa, com especificidade exploratória, por proporcionar a compreensão dos fenômenos sociais e culturais. Foi verificado que a região é carente de infraestrutura básica, todavia se destaca como importante território por sua vasta riqueza ecológica, arqueológica e paisagística. Notou-se que o Conselho Gestor da Unidade de Conservação é atuante e que diferentes ações estão sendo realizadas junto à comunidade, com práticas de valorização e sustentabilidade dos recursos naturais e culturais para o fortalecimento do território e ordenamento do turismo. Considerando que tudo funciona dentro de uma cadeia, infere-se que, ao fomentar o Turismo Sustentável na APA Baía Negra, o poder público, o terceiro setor, e parceiros da iniciativa privada, possam contribuir para o empoderamento da comunidade e corroboram no alcance dos Objetivos do Desenvolvimento Sustentável (ODS).
\end{abstract}

PALAVRAS CHAVE: Comunidades Tradicionais; Ecoturismo; Gestão Participativa.

ABSTRACT: The present study aims to identify the potential of the Baía Negra Environmental Protection Area, located in Ladário Municipality, in the Pantanal of Mato Grosso do Sul, for the practice of sustainable tourism as an alternative to local development. The study was conducted through qualitative research with exploratory specificity because it provides an understanding of social and cultural phenomena. It was verified that the region is lacking in basic infrastructure, but stands out as an important territory due to it is vast ecological, archaeological, and landscape richness. It was noted that the Management Council of the Conservation Unit is active and that different actions are being carried out with the community, with the practices of valorization and sustainability of natural and cultural resources for the strengthening of the territory and tourism planning. Considering that everything works within a chain, it is inferred that by fostering sustainable tourism in the APA Baía Negra, the Government, the third sector, and partners of the private initiative, can contribute to the empowerment of the community and corroborate the reach of the Objectives of Sustainable Development (OSD).

KEYWORDS: Traditional Communities; Ecotourism; Participatory Management. 


\section{Introdução}

Presente no Sistema Nacional de Unidades de Conservação da Natureza (SNUC - Lei no 9.985/2000), as Áreas de Proteção Ambiental (APAs) estão inseridas na categoria de Uso Sustentável e têm como objetivo principal compatibilizar a conservação da natureza com o uso sustentável de parcela dos seus recursos naturais. Geralmente, são áreas extensas com certo grau de ocupação humana e dotadas de atributos naturais importantes para a qualidade de vida e o bem-estar da população (BRASIL, 2000).

A Área de Proteção Ambiental (APA) Baía Negra é a primeira Unidade de Conservação de Uso Sustentável no Pantanal, que agrega a conservação ambiental e sobrevivência das populações tradicionais (PML, 2016). Essas populações são definidas como grupos culturalmente diferenciados, com formas próprias de organização social, que ocupam e usam territórios, recursos naturais como condição para sua reprodução cultural, social, religiosa, ancestral e econômica, utilizando conhecimentos, inovações e práticas geradas e transmitidas pela tradição (BRASIL, 2007).

Nesse contexto, a prática do turismo sustentável pode ser sinalizada como uma possibilidade de desenvolvimento dessas regiões, haja vista que implica em ações socialmente justas, economicamente viáveis e ecologicamente corretas. Para tanto o desenvolvimento do turismo deve ser estabelecido e adequado de maneira a harmonizar essas três dimensões para garantir sua sustentabilidade a longo prazo (NHUTA, 2015).

Todavia, o turismo sustentável não representa uma forma especial de turismo, e tem como premissa abranger todos os tipos de turismo em quaisquer destinos (UNEP, 2005). É considerado uma atividade que visa satisfazer as necessidades dos turistas e as necessidades socioeconômicas das regiões receptoras, por meio da manutenção cultural, ambiental e da diversidade biológica, para que estas sejam conservadas para as presentes e futuras gerações (OMT, 2001). Assim, é caracterizado como um modelo de desenvolvimento turístico, orientado pelos princípios da economia solidária, valorização da cultura local, protagonizado pelas comunidades locais (SANSOLO; BURSZTYN; 2009).

Nesse sentido, é importante ressaltar que, para todo o crescimento, deve existir uma oportunidade inclusiva, devido à capacidade turística de criação de emprego, redução da pobreza, desenvolvimento humano e sustentabilidade ambiental (NHUTA, 2015).

Buscou-se responder a seguinte questão norteadora: a prática do turismo sustentável pode contribuir como agente transformador da realidade da APA Baía Negra e possibilitar o desenvolvimento e o protagonismo da comunidade local?

O presente estudo tem como objetivo identificar o potencial da Área de Proteção Ambiental Baía Negra, em Ladário, Mato Grosso do Sul, para a prática do turismo sustentável, como alternativa de desenvolvimento da região.

Portanto, sua relevância consiste na compreensão de que o desenvolvimento do turismo em bases sustentáveis é capaz de desempenhar múltiplos benefícios para as regiões, e especialmente por conciliar os valores sociais, econômicos e ambientais. 


\section{Material e Métodos}

\section{Caracterização da área de estudo}

A Área de Proteção Ambiental Baía Negra (1901'18.8"S e 57³0'39.3"W) está localizada em Ladário, cidade mais antiga do estado de Mato Grosso do Sul (Figura 1). A região é caracterizada por apresentar diversidade de relevos, com destaque para o Maciço do Urucum. A APA está inserida no complexo do Pantanal, uma das maiores áreas alagadas contínuas do mundo, reconhecida como Reserva da Biosfera e Patrimônio Natural da Humanidade pela UNESCO (WIDMER; PIRES, 2008), cenário que abriga uma abundante biodiversidade, caracteriza-se como um dos destinos turísticos brasileiros mais procurados pelo turismo nacional e internacional.

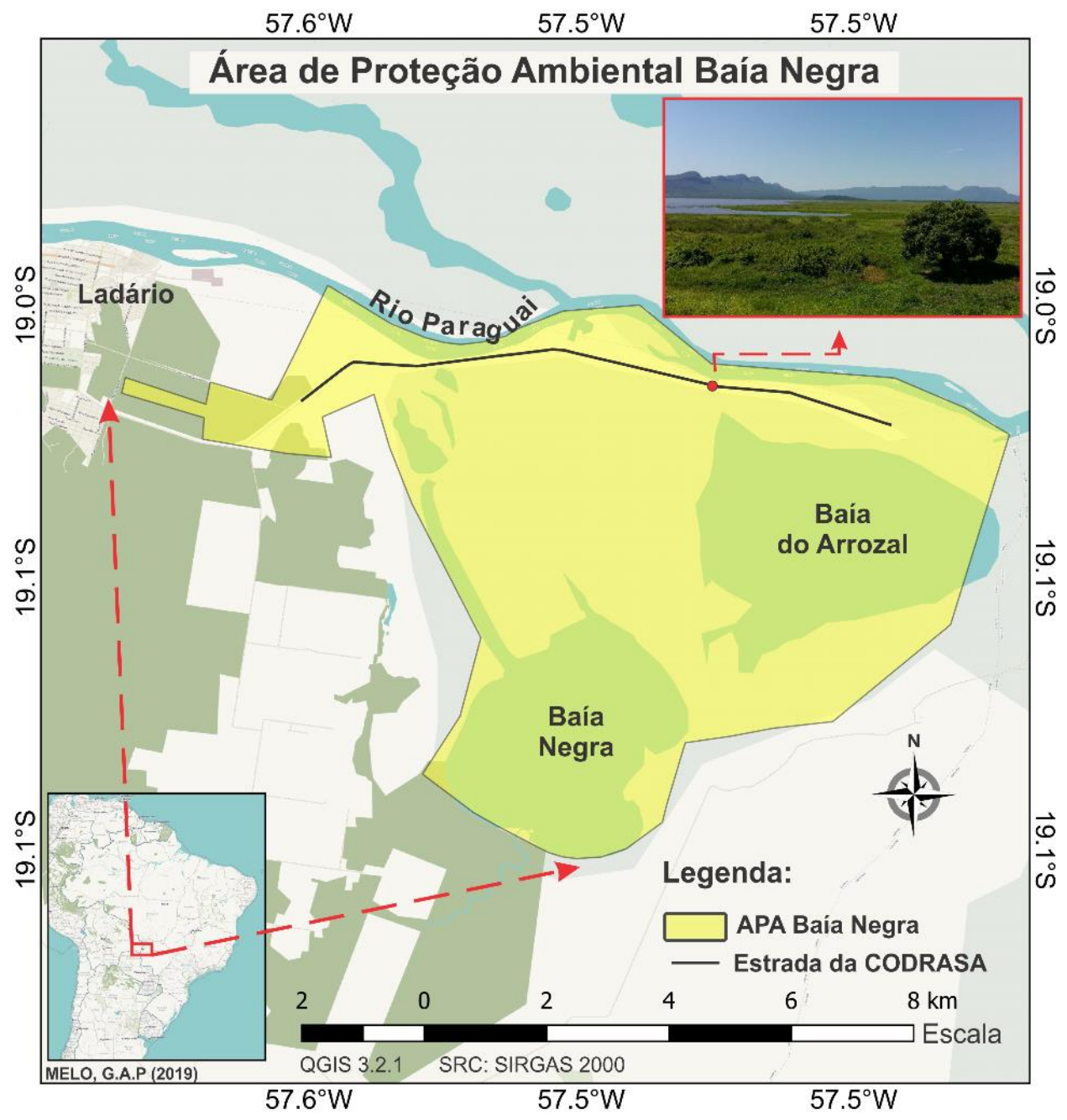

Figura 1: Mapa de Situação e Localização da APA Baía Negra.

Figure 1: Map of Situation and Location of APA Baía Negra.

Fonte: elaborado pelos autores (2019).

Source: elaborated by the authors (2019).

A APA Baía Negra foi criada por meio do Decreto 1.735/2010, pelo Poder Executivo de Ladário, sua gestão é designada à esfera municipal. Possui uma extensão territorial aproximada de 6.000 hectares. A área foi incorporada ao patrimônio da União conforme a Lei 8.029/90. Abriga o $6^{\circ}$ Distrito Naval da Marinha do Brasil, nos limites sul e oeste da APA. 
Na área residem 52 famílias, segundo uma análise realizada em 2015, e depois divulgada no Plano de Manejo da APA. Os moradores desenvolvem atividades de guias; piloteiros de pequenas embarcações; aluguéis de embarcações; e da pesca artesanal com captura de iscas, vendidas para o turismo de pesca. Também desenvolvem atividades de subsistência, como a manutenção de pequenas culturas (arroz, milho, abóbora e hortaliças); e da criação de gado de corte ou leiteiro.

O acesso à APA Baía Negra pode ser a partir de Campo Grande, capital do estado, pela Rodovia BR 262, sentido oeste, em direção às cidades de Corumbá e Ladário. Também em sua porção sul e oeste, a partir da Estrada Parque Pantanal. Outra forma se dá pelo seu limite oeste, rio Paraguai, com a utilização de embarcações e de atracadouros localizados em propriedades ribeirinhas e nos empreendimentos ao longo do rio.

Existem estruturas físicas na APA possíveis para uso público e que podem ser voltadas para a prática do Ecoturismo de Base Comunitária, tais como: a sede da APA; hotéis/pousadas; ranchos; atracadouros; Base da Marinha do Brasil; e cultivos comunitários, como hortas e viveiros.

A APA também abriga a base de estudos da Universidade Federal da Grande Dourados - UFGD, destinada a atender estudantes, técnicos e professores. Ela foi estruturada especialmente para receber a comunidade acadêmica para a realização de pesquisas relacionadas ao Pantanal.

\section{Instrumentos de Coleta de Dados}

O estudo foi conduzido por meio da pesquisa qualitativa e objetivo exploratório, visto que tem como ponto principal entender, descrever e, algumas vezes, explicar os fenômenos de grupos sociais e indivíduos, e por proporcionar mais informações sobre o assunto, uma vez que a pesquisa se encontra na fase preliminar e permite uma análise do tema sob diferentes ângulos e aspectos (PRODANOV; FREITAS, 2013).

Além disso, foi utilizado como documento principal o Plano de Manejo da Unidade de Conservação (2016), agrupado em três encartes. O primeiro trata da caracterização geral da APA Baía Negra; o segundo apresenta o diagnóstico ambiental; e o terceiro versa sobre o planejamento da APA. Além de informações contidas no Programa de Educação Ambiental e Comunicação da Área de Proteção Ambiental Baía Negra para o exercício de 2019, que tem como objetivo promover a sensibilização dos moradores da APA e da população do entorno sobre 0 reconhecimento dos atrativos oferecidos no local, bem como, contribuir para que todos os moradores compreendam o que é uma Unidade de Conservação, e com isso desenvolvam um sentido de pertencimento de onde vivem.

O roteiro de visita técnica foi elaborado com vistas a possibilitar conhecer o local de interesse do estudo, e a delimitação espacial levou em consideração as especificidades ambientais.

Em dezembro de 2018 foram realizadas verificações in loco, assistidas por residentes da comunidade, para a coleta dos elementos indicativos para a prática do turismo sustentável na APA Baía Negra. 


\section{Resultados e Discussão}

Ao realizar o levantamento sobre as características ambientais da APA Baía Negra, foi constatado que já existe a prática turística na região, representada pela modalidade do turismo de pesca esportiva, dada a riqueza dos recursos hídricos.

De modo geral, o segmento de turismo de pesca esportiva é formatado como uma indústria que movimenta a economia de diferentes locais (BANDUCCI JÚNIOR, 2003). Entretanto, os maiores favorecidos nessa atividade são os donos de pousadas, hotéis, restaurantes, barcos hotéis e chalanas.

Também é mencionado por Banducci Júnior (2003), que, além de acontecer pesca predatória, podem ser observados impactos ambientais negativos nos corpos hídricos da região, notado pela quantidade de resíduos sólidos habitualmente descartados às margens do rio Paraguai e das baías que integram a Área de Proteção Ambiental.

Em alguns destinos, devido aos grupos masculinos que constituem o público-alvo do turismo de pesca, ocorrem consequências negativas de prostituição (GARCIA et al., 2016), circunstâncias que impactam desfavoravelmente as comunidades ribeirinhas.

No caso da APA Baía Negra, essa informação de casos de prostituição não foi mencionada pela comunidade. Das ameaças relatadas, citam-se a pesca predatória, redução do estoque pesqueiro, ocupação irregular, descarte irregular do lixo, queimadas, caça ilegal, desmatamento, atropelamentos de animais por pessoas não residentes e a falta de saneamento básico (PML, 2016).

De acordo com o diagnóstico da UC, relatado no Plano de Manejo, toda ameaça gera uma possível oportunidade, dentre as quais foram citadas: turismo como fonte de renda da comunidade (guias e piloteiros); extrativismo (arroz, fibras, frutos, iscas e pescado); comércio (restaurantes, pousadas e artesanato); cultura (horta, viveiro de mudas nativas, apicultura e piscicultura); e moradias dotadas de saneamento básico (infraestrutura).

Para tanto, ao realizar a análise preliminar sobre a prática do turismo sustentável, como alternativa de desenvolvimento da região da APA Baía Negra, infere-se que à medida que os tomadores de decisões se conscientizam das desvantagens do turismo desordenado, eles devem procurar um planejamento alicerçado na gestão e desenvolvimento alternativo do turismo (CHOI; SIRAKAYA, 2006). Ao passo que as pessoas tenham mais conhecimento acerca do tema turismo sustentável, elas podem se tornar agentes e multiplicadores de práticas que beneficiem o meio ambiente, as comunidades locais e, por conseguinte os destinos (BRASIL, 2016).

Isso se constata quando a OMT (2001) menciona que o turismo sustentável visa o desenvolvimento das regiões, e por onde essa prática é realizada é possível garantir melhores oportunidades para as comunidades receptoras. Face a isso, foi realizado um levantamento de elementos existentes na APA Baía Negra (Quadro 1) que representam um potencial para a prática do turismo sustentável como alternativa de desenvolvimento da região. 
Quadro 1: Características que favorecem à prática do turismo sustentável na APA Baía Negra.

Framework 1: Characteristics that favor the practice of sustainable tourism in the APA Baía Negra.

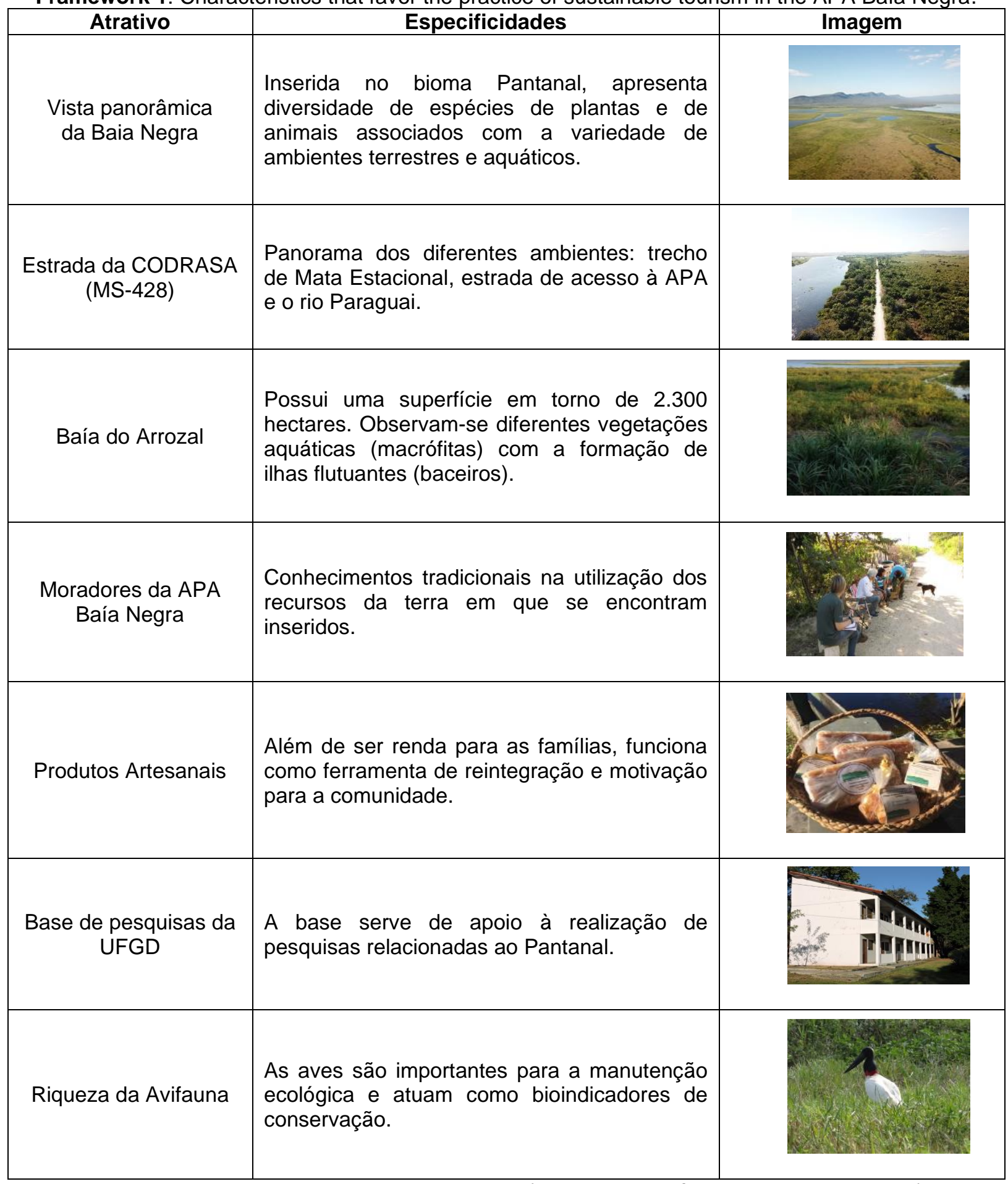

Fonte: elaborado com base nas visitas in loco (acervo APA Baía Negra e autores, 2018).

Source: based on visits in loco (collection APA Baía Negra and authors, 2018).

Uma dessas características é a contemplação da vida silvestre, considerada de grande importância e muito praticada por turistas de diferentes partes do mundo (RECK; MARTINEZ, 2010). Existem na APA Baía Negra 11 espécies de mamíferos (PM, 2016), sendo possível encontrar animais como a onça-pintada (Panthera onca), anta (Tapirus terrestris), veado-catingueiro (Mazama gouazoubira), cateto (Tayassu 
tajacu), lontra (Lontra longicaudis), macaco-prego (Sapajus cay), macaco-da-noite (Aotus azarae) e o bugio (Alouatta caraya).

Outra particularidade é a avifauna da região. Esta é rica e abundante, que indica atrativo potencial de desenvolvimento da região, devido à prática do turismo de observação de aves. Na região foram registradas 135 espécies (PML, 2016), com expectativa de aumento devido à ocorrência na extensão territorial do Pantanal, com quase 600 espécies (NUNES, 2011).

Em vista disso, foi organizado pelo Clube de Observadores de Aves do Pantanal uma cartilha que traz algumas espécies de aves da APA Baía Negra, além de informações importantes para o público de observadores de aves.

Ressalta-se que os observadores de aves ou birdwatchers são considerados um nicho de mercado substancialmente importante, tanto para o aspecto econômico, como para o ambiental. E, certamente, quando a comunidade está envolvida nesse processo e atua com a participação de monitores e guias desses turistas, o aspecto social também é representado e beneficiado nessa integração dos pilares da sustentabilidade.

Nesse contexto, Dias (2011) enfatiza que localidades que possuem áreas propícias para observar aves, tanto pelas suas características de biodiversidade ou alto endemismo, deveriam transformar essa riqueza natural em recurso econômico para melhorar a qualidade de vida de seus habitantes.

Pesquisas científicas são previstas nesse tipo de Unidade de Conservação, e no caso da APA Baía Negra podem ser observadas características interessantes de serem reconhecidas para a realização de investigação científica em diferentes áreas do conhecimento.

Embora a APA seja carente de infraestrutura básica como saneamento, iluminação pública na estrada, falta de água encanada, esgoto ou coleta de resíduos sólidos, transporte público, espaço de recreação para a comunidade, representando aspectos negativos da região, a área se caracteriza como um importante território que dispõe de vasta riqueza ecológica, arqueológica e paisagística (PML, 2016), além do potencial cultural da comunidade, que possui saberes e habilidades tradicionais de sua biodiversidade, a relação de respeito entre a comunidade e a natureza favorece a conservação ambiental, sem a destruição dos recursos naturais, possibilitando uma gestão sustentável.

Todavia, é fundamental que a implementação das atividades turísticas seja delineada com foco na valorização local e no empoderamento da comunidade, visto que o seu desenvolvimento é um processo socializante no qual as comunidades envolvidas são protagonistas de seu tempo e espaço (CRUZ, 2009).

Dentre os principais objetivos de criação da APA Baía Negra, apontados no Plano de Manejo, destaca-se a implementação do ordenamento do turismo para a realização de atividades de valorização e sustentabilidade dos recursos naturais e culturais. No tocante, é necessário um planejamento intenso e contínuo com a comunidade, pois as atividades turísticas transformam o espaço e altera as relações dos moradores locais que passam a fazer parte da produção de bens e serviços da própria atividade, e com isso o turismo assume o papel de agente modificador da realidade (MEDEIROS; MORAIS, 2013). 
Vale ressaltar que um planejamento responsável do turismo inclui elementos, como: a responsabilidade na prática do turismo; sustentabilidade do destino; e qualidade de vida, tal planejamento atua como fator mediador, enquanto sustentabilidade da comunidade (SARISKUMAR; BHAVAN, 2018).

Assim, o turismo sustentável pode ser uma alternativa para as comunidades modificarem sua economia de subsistência, combinando formas antigas e novas de manter e promover sua identidade, sem se opor à evolução da sociedade e de seus sistemas econômicos (DIEGUES, 2008), visto que, essa prática oferece oportunidades para pessoas com várias desvantagens sociais, além de fornecer empregos para trabalhadores com pouco ou nenhum treinamento, condição que outros setores não acolhem (MTAPURI; GIAMPICCOLI, 2016).

Com o propósito de auxiliar a gestão da UC no processo de desenvolvimento e integrá-la à população e às ações realizadas em seu entorno, o Conselho Gestor da APA Baía Negra prossegue com esse intuito e tem em sua composição a Fundação de Meio Ambiente de Ladário, Instituto Brasileiro do Meio Ambiente e dos Recursos Naturais Renováveis (IBAMA), Marinha do Brasil, Instituto de Meio Ambiente de Mato Grosso do Sul (IMASUL), Empresa Brasileira de Pesquisa Agropecuária (EMBRAPA), Universidade Federal de Mato Grosso do Sul (UFMS), Universidade Federal da Grande Dourados (UFGD), ONG Ecoa e a Associação dos Moradores da APA.

Foi constatado que o Conselho Gestor da Unidade de Conservação é atuante e que diferentes ações estão sendo realizadas junto à comunidade, com práticas de valorização e sustentabilidade dos recursos naturais e culturais para 0 fortalecimento do território e ordenamento do turismo. Dentre as quais:

- Brigada Comunitária de Combate a Incêndios Florestais da APA Baía Negra;

- Mulheres na formação de brigada comunitária para prevenção e combate a incêndios florestais;

- Exibição do filme documentário "Baía Negra, vidas do Pantanal", em diferentes instituições locais;

- Participação da Associação de Mulheres Produtoras da APA Baía Negra no Colóquio de Sustentabilidade: Mulheres Ribeirinhas e os Produtos da Biodiversidade Pantaneira;

- Oficina de desenho com as crianças para a criação do mascote da APA Baía Negra, para utilização em materiais educativos e informativos;

- Criação de abelhas nativas sem ferrão;

- Criação de horta comunitária; e

- Retirada dos resíduos sólidos descartados inadequadamente na área APA.

Todas essas ações foram realizadas com proposta de aumentar o diálogo e a confiança entre o órgão gestor e a comunidade local, e com a finalidade de integrar os atores sociais que estão vinculados de maneira direta e indireta à APA. 
Ainda com o propósito de corroborar com o desenvolvimento da região, a Organização Não Governamental ECOA (Ecologia e Ação), cuja missão principal é promover ações socioambientais para conservação dos ambientes naturais e de suas populações locais, tem realizado levantamentos de dados e informações por meio do projeto ECCOS (Ecorregiões Conectadas, Conservadas e Sustentáveis) para aplicar um pacote de ações e propostas à comunidade da APA Baía Negra. Além disso, o uso de mecanismos de gestão para o alinhamento para promover atividades produtivas das famílias residentes e, consequentemente, o fortalecimento desse território.

Outra instituição que tem contribuído para esse desenvolvimento é o Instituto Mamede de Pesquisa Ambiental e Ecoturismo (IMPAE), com a realização de cursos de campo com enfoque na biodiversidade do Pantanal e ciência cidadã, ofertados aos acadêmicos do ensino superior, por meio de práticas de conservação da biodiversidade e ações socioambientais que valorizam os moradores da comunidade local, enquanto agentes de conservação. Como também, no fortalecimento da realização de pesquisas científicas na região, integrando diferentes áreas do conhecimento.

Além disso, o IMPAE junto ao Conselho gestor planeja cursos para os moradores da APA, nos quais trazem como propostas a Formação de Condutores de Visitantes de Unidades de Conservação. Essa ação está em acordo com o calendário do Programa de Educação Ambiental e Comunicação da Área de Proteção Ambiental Baía Negra, para o exercício de 2019.

Vale destacar que os condutores de visitantes em roteiros interpretativos (no sentido turístico e educativo) são fundamentais, pois, eles são os principais elos entre os visitantes e o local que está sendo visitado (MOREIRA; BIGARELLA, 2008).

Enfatiza-se que, embora a organização social se caracterize como um dos maiores desafios na promoção do desenvolvimento do turismo sustentável (NOGUEIRA, 2011), e apesar da importância das participações dos moradores da APA, em palestras, reuniões, atividades, e a compreensão do conceito de uma Unidade de Conservação se caracterizar como insuficiente, é necessário dedicar um esforço contínuo à comunidade.

Sendo assim, as ações de planejamento desse processo devem ser implementadas e geridas em harmonia com as tradições e os valores culturais dos moradores da APA Baía Negra, e deverão ser estruturadas por meio do associativismo e parcerias, para que a comunidade se torne a real beneficiada dessa iniciativa.

Por essa razão, apontam-se atividades que podem ser realizadas na APA Baía Negra (Quadro 2), por representarem práticas turísticas sustentáveis, como alternativas de desenvolvimento da região, e por configurarem baixo impacto, menor desgaste possível ao ambiente natural e para a comunidade, respeitando suas regras, cultura e principalmente a tranquilidade do local. 
Quadro 2: Práticas sustentáveis de turismo que podem ser realizadas na APA Baía Negra.

Framework 2: Sustainable tourism practices that can be carried out at APA Baía Negra.

\begin{tabular}{|c|l|}
\hline Atividades & \multicolumn{1}{|c|}{ Características } \\
\hline $\begin{array}{c}\text { Observação de aves e da } \\
\text { vida silvestre }\end{array}$ & $\begin{array}{l}\text { Consolidada em diferentes países, a atividade é geradora de } \\
\text { benefícios ambientais, econômicos e sociais. }\end{array}$ \\
\hline Trilhas & $\begin{array}{l}\text { Oferecem diversos benefícios para a saúde física e mental, além de } \\
\text { promoverem o contato com a natureza. }\end{array}$ \\
\hline $\begin{array}{c}\text { Contemplação de } \\
\text { paisagens }\end{array}$ & $\begin{array}{l}\text { Atividade que está diretamente relacionada à satisfação, à } \\
\text { compreensão do meio e a possibilidade de viver e sentir a natureza. }\end{array}$ \\
\hline Cicloturismo & $\begin{array}{l}\text { Proporciona experiências múltiplas, maneira saudável, econômica e } \\
\text { ecológica de se fazer turismo. }\end{array}$ \\
\hline $\begin{array}{c}\text { Difusão cultural (saberes e e } \\
\text { fazeres) }\end{array}$ & $\begin{array}{l}\text { Representam componentes intangíveis que moldam a diversidade e } \\
\text { estabelecem a identidade de um povo, repassados de geração a } \\
\text { geração. }\end{array}$ \\
\hline $\begin{array}{c}\text { Comercialização de } \\
\text { artesanato }\end{array}$ & $\begin{array}{l}\text { A produção artesanal contribui para singularizar a identidade cultural } \\
\text { local e propicia uma ocupação de renda para as famílias. }\end{array}$ \\
\hline $\begin{array}{c}\text { Turismo Científico } \\
\text { Resopicia compreender as características do território e os costumes } \\
\text { da comunidade, numa forma dinâmica para a realização de estudos } \\
\text { e pesquisas de caráter científico. }\end{array}$ \\
\hline $\begin{array}{c}\text { Restaurante e/ou meio de } \\
\text { hospedagem comunitário }\end{array}$ & $\begin{array}{l}\text { Empreendimentos de economia social que geram ocupação para a } \\
\text { comunidade e valorizam a distribuição equitativa dos recursos } \\
\text { provenientes dos serviços turísticos ofertados. }\end{array}$ \\
\hline
\end{tabular}

Fonte: Elaborado pelos autores.

Source: elaborated by the authors.

Vale ressaltar que quaisquer modificações da APA para uso múltiplo ocorrerão impactos relacionados à exposição (PML, 2016). Embora haja impactos negativos nesse processo, Scheyvens (1999) destaca que é possível mencionar impactos positivos para a comunidade, tais como: o empoderamento social, psicológico, econômico e o empoderamento político.

Também, é necessário apresentar que os impactos dos empreendimentos nas comunidades locais devem enfatizar a importância dessas comunidades desempenharem algum controle e compartilhar os benefícios das iniciativas de ecoturismo em sua área (SCHEYVENS, 1999).

Em razão disso, os agentes do desenvolvimento turístico devem impor limitações das atividades, quando elas forem exercidas em áreas particularmente sensíveis (OMT, 1999). Nesse ponto de vista, Choi e Sirakaya (2006) sinalizam que o ambiente natural deve ser protegido pelo seu valor intrínseco e como um recurso para as presentes e futuras gerações, além da sustentabilidade sociocultural que implica em respeito pela identidade social, pela cultura da comunidade e seus bens.

Por esse ângulo, o poder público municipal tem um papel importante nesse processo, com o compromisso de estabelecer as diretrizes a serem articuladas para o ordenamento do desenvolvimento turístico e, sobretudo, apoio à implementação.

Considerando que tudo funciona dentro de uma cadeia, infere-se que, ao fomentar o Turismo Sustentável nessa região, o poder público, o terceiro setor, e parceiros da iniciativa privada podem contribuir com os Objetivos do Desenvolvimento Sustentável (ODS), criado pela Organização das Nações Unidas em 2015, que por meio de uma agenda mundial foram formatadas 169 metas e ações, dentre as quais visam acabar com a pobreza, promover uma gestão sustentável dos recursos naturais, o crescimento econômico inclusivo e sustentável, 
qualidade de vida, bem-estar para as populações e a proteção do meio ambiente. $\mathrm{E}$ nesse caso o turismo é sinalizado como essencial para o alcance dos 17 Objetivos.

Segundo a Plataforma Roteiro do Turismo da Organização Mundial do Turismo (UNWTO), para o Crescimento Inclusivo em 2030, o turismo desempenha um papel vital para os ODS, haja vista que o turismo pode promover a infraestrutura, promover a regeneração e conservação do patrimônio cultural e natural, ativos dos quais o turismo depende.

Todavia, o desenvolvimento de um turismo sustentável depende da participação comunitária, e com efeito melhore o padrão de vida dessa comunidade, e com isso estimule a provisão de infraestrutura para a região e instalações turísticas para receberem grupos de turistas (BAKER, 2017).

Dessa maneira, a APA Baia Negra, objeto deste estudo, poderá se tornar referência, assim como outras APAs existentes em diferentes regiões do Brasil, dentre elas:

- APA do Jalapão, no estado do Tocantins, gerida pelo Instituto Natureza do Tocantins, criada no ano 2000, possui 461.730 hectares. Sua abrangência ocupa terras dos municípios de Mateiros, Novo Acordo e Ponte Alta do Tocantins;

- APA Serra das Areias, no estado do Goiás, criada em 2015, gerida pelo poder municipal de Aparecida de Goiânia, possui 2.890 hectares; e

- APA de Guaraqueçaba, estado do Paraná, criada em 1992, abrange uma área de 191.596, gerida pelo Instituto Ambiental do Paraná.

Destacam-se também as Áreas de Proteção Ambiental geridas pelo poder federal, representadas pelo Instituto Chico Mendes de Conservação da Biodiversidade (ICMBio):

- APA de Cairuçu, no estado do Rio de Janeiro, foi criada em 1983, abrange área de 33.800 hectares. Está situada no município de Paraty, Rio de Janeiro, município elevado à categoria de Patrimônio Mundial da Humanidade da Unesco; e

- APA Chapada do Araripe abrange os estados de Pernambuco, Ceará e Piauí. Foi criada em 1997, sua área é de 972.605,18 hectares, estendida em 33 Municípios.

Todas essas áreas foram criadas com a finalidade de proteger a diversidade biológica, disciplinar o processo de ocupação e o uso sustentável dos recursos naturais, de forma a garantir a conservação das comunidades tradicionais e incentivar o aproveitamento sustentável do potencial turístico dessas regiões. Logo, isso pressupõe que as práticas sustentáveis devem ser alinhadas em ações economicamente viáveis, socialmente justas, ecologicamente corretas e culturalmente diversas.

Haja vista que uma autêntica organização para um turismo sustentável deve incluir comunidade anfitriã, qualidade de vida, equidade, proteção ambiental, integridade cultural e experiência para os visitantes (NHUTA, 2015). 
Empreender o turismo sustentável na APA Baía Negra representará muito mais do que um meio de renda extra para a comunidade, será uma maneira de divulgar a realidade e manter viva a sua identidade. Além disso, fortalecer o respeito e a conservação da natureza e o modo de vida local. Pois, quando esse planejamento ocorre baseado na participação e com 0 protagonismo da comunidade, o desenvolvimento do turismo contribui substancialmente e produz grandes benefícios, por ter como base os pilares da sustentabilidade, que compreende o econômico, social e o ambiental (MAGRI et al., 2018).

Portanto, o desenvolvimento do turismo sustentável na comunidade da APA Baía Negra pode refletir uma composição contra-hegemônica bem-sucedida, diante das regras do turismo convencional, reforçando que desenvolvimento e conservação podem caminhar juntos.

\section{Considerações Finais}

O estudo apontou diferentes elementos que configuram potenciais para o desenvolvimento do turismo sustentável na região da APA Baía Negra, caracterizada pelo território inserido no Pantanal, área prioritária para a conservação da biodiversidade. Dispõe de ampla riqueza ecológica e paisagística, bem como, aspectos culturais da comunidade e seu conhecimento tradicional.

Nesse enfoque, para o desenvolvimento de turismo sustentável na região, é necessário que o planejamento se torne um instrumento contínuo que favoreça o conhecimento do território, e possa envolver e beneficiar os diferentes arranjos locais, além de reforçar a construção e reconstrução cultural entre gerações da comunidade.

Apesar da APA Baía Negra passar por diferentes desafios, fatores que podem refletir negativamente no desenvolvimento de atividades turísticas, sugere-se o contínuo envolvimento de todos os atores sociais ligados à gestão da APA, a fim de mitigar e buscar soluções para a promoção de ações mais efetivas que possam favorecer o turismo sustentável.

Portanto, sendo o turismo sustentável uma forma ideal de fazer turismo, haja vista que essa modalidade é alicerçada nos princípios que prezam pela conservação ambiental e pela repartição equitativa dos benefícios econômicos, é possível construir uma relação benéfica entre a comunidade, órgãos e instituições presentes na APA Baía Negra, a partir de uma nova economia que propiciará desenvolvimento para a região e a garantia de manutenção dos saberes tradicionais.

\section{Referências}

BANDUCCI JÚNIOR, A. Turismo cultural e patrimônio: A memória Pantaneira no curso do Rio Paraguai. Horizontes Antropológicos, Porto Alegre, 9(20): 117-140, 2003.

BAKER, J. Tourismification and Integration of Buganda's Culture in Community Socio-economic Activities for Poverty Reduction and Sustainable Development. Journal of Environmental Science and Engineering, v. 6, p. 98-109, 2017. 
BRASIL. Ministério do Turismo. Turismo e sustentabilidade: orientações para prestadores de serviços turísticos. Brasília: Ministério do Turismo, 2016.

BRASIL. República Federativa do Brasil. Decreto n. 6.040, de 7 de fevereiro de 2007, Institui a Política Nacional de Desenvolvimento Sustentável dos Povos e Comunidades Tradicionais. Brasília: Congresso Nacional, 2007.

BRASIL. Lei no 9.985, de 18 de julho de 2000. Institui o Sistema Nacional de Unidades de Conservação da Natureza. Diário Oficial da República Federativa do Brasil, Brasília, 2000.

CHOI, H. C.; SIRAKAYA, E. Sustainability indicators for managing community tourism. Tourism Management, v. 27, p. 1274-1289, 2006.

CRUZ, R. C. A. Turismo, produção do espaço e desenvolvimento desigual: para pensar a realidade brasileira. In: BARTHOLO, R.; SANSOLO, D. G.; BURSZTYN, I. Turismo de Base Comunitária diversidade de olhares e experiências brasileiras. Rio de Janeiro: Letra e imagem, 2009. p. 92-107.

DIAS, R. A biodiversidade como atrativo turístico: o caso do Turismo de Observação de Aves no município de Ubatuba (SP). Revista Brasileira de Ecoturismo, São Paulo, v.4, n.1, 2011, p.111-122, 2011.

DIEGUES, A. C. O mito moderno da natureza intocada. São Paulo: Hucitec, 2008.

ECOA. Ecologia e Ação. Aniversário da Área de Proteção Ambiental (APA) Baía Negra 2018. Disponível em: <http://ecoa.org.br/8o-aniversario-da-apa-baia-negra/>. Acesso em: 10 jan. 2019.

GARCIA, C. B.; POLETTO, C. W. R.; PARRELA, E. C. L.; RIBAS, N. O turismo de pesca no município de Miranda-MS. Multitemas, n. 27, p. 167-168, 2016.

IMPAE. Instituto Mamede de Pesquisa Ambiental e Ecoturismo. Curso de Biologia de Campo e Ciência Cidadã no Pantanal. Disponível em: < https://instituto mamede.blogspot.com/search?q=Ba\%C3\%ADa>. Acesso em: 1 fev. 2019.

MAGRI, T. C. S.; CARVALHO, R. C. R.; MAGRI, R. A. F.; ANDRADE, C. O. P. Mapeamento, classificação e certificação de rotas de trekking em uma área do Parque Nacional da Serra da Canastra (MG). Revista Brasileira de Ecoturismo, São Paulo, v.11, n.4, p.645-672, 2018.

MEDEIROS, L. D.; MORAIS, P. E. Turismo e Sustentabilidade Ambiental: Referências para o Desenvolvimento de um Turismo Sustentável. Revista Meio Ambiente e Sustentabilidade, v. 3, n. 2, p.198-234, 2013.

MTAPURI, O.; GIAMPICCOLI, A. Towards a comprehensive model of communitybased tourism development, South African Geographical Journal, v. 98, n.1, p. 154-168, 2016.

MOREIRA, J. C.; BIGARELLA, J. J. Interpretação ambiental e geoturismo em Fernando de Noronha-PE. In: CASTILHO, C. J. M.; VIEGAS, J. Turismo e práticas socioespaciais: múltiplas abordagens e interdisciplinaridades. Recife: Editora da UFPE, p. 171-192, 2008.

NHUTA, S. Tourism and Sustainanble Development: perpectives and learning for a sustainable future. Conferência Internacional da Midlands State University Victoria Falls. Midlands, p. 1-18, 2015 
NOGUEIRA, S. M. B. Ações sustentáveis para o desenvolvimento do ecoturismo em unidades de conservação. In. TELES, R. M. S. Turismo e meio ambiente. Rio de Janeiro: Elsevier, 2011. p. 61-86

NUNES, A. P. Quantas espécies de aves ocorrem no Pantanal brasileiro. Atualidades Ornitológicas, v. 160, p. 45-54, 2011.

OMT. Organização Mundial do Turismo. Turismo Sustentável. In: Introdução ao Turismo. São Paulo: Roca, 2001. p.243-260.

OMT. Organização Mundial do Turismo. O turismo, fator de desenvolvimento

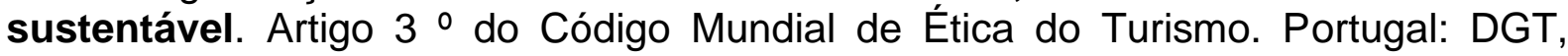
1999.

ONU. Organização das Nações Unidas. Objetivos do Desenvolvimento Sustentável - ODS. Disponível em: <https://nacoesunidas.org/pos2015/ agenda2030/>. Acesso em: 10 jan. 2019.

PML. Prefeitura Municipal de Ladário. Plano de Manejo APA Baía Negra. Disponível em: <http://www.ladario.ms.gov.br/pagina/plano-de-manejo-apa-baianegra>. Acesso em: $20 \mathrm{dez} .2018$.

PRODANOV, C. C.; FREITAS, E. C. Metodologia do Trabalho Científico: métodos e técnicas da pesquisa e do trabalho acadêmico. Novo Hamburgo: Feevale, 2013.

RECK, G., MARTÍNEZ, P. Áreas protegidas: ¿Turismo para la conservacion o conservacion para el turismo? Polémika, v. 2, n. 5, p. 86-95, 2010.

SANSOLO, D. G.; BURSZTYN, I. Turismo de base comunitária potencialidade no espaço rural brasileiro. In: BARTHOLO, R.; SANSOLO, D.G.; BURSZTYN, I. Turismo de Base Comunitária diversidade de olhares e experiências brasileiras. Rio de Janeiro: Letra e imagem, p. 142 - 161, 2009.

SARISKUMAR, N.; BHAVAN, T. The impact of responsible tourism on destination sustainability and quality of life in Passikudah tourism destination. International Journal of Social Science and Economic Research, v. 03, n. 11, p. 5933- 5959, 2018.

SCHEYVENS, R. Ecotourism and the empowerment of local communities. Tourism Management, v. 20, p. 245-249, 1999.

TOURISM FOR SDGS. Roteiro do Turismo da UNWTO para o Crescimento Inclusivo em 2030. Disponível em: <http://tourism4sdgs.org/>. Acesso em: 20 jun. 2019.

WIDMER, G. M.; PIRES, M. J. O turismo como fator de contribuição para a proteção e função social do patrimônio natural da humanidade. Revista Hospitalidade. São Paulo, n. 2, p. 52-64, 2008.

UNEP - WTO. United Nations Environment Programme and World Tourism Organization. Making tourism more sustainable. A guide for policy makers. UNEP: Paris, 2005. 210p. 


\section{Agradecimentos}

Ao Programa de Pós-Graduação em Meio Ambiente e Desenvolvimento Regional da Universidade para o Desenvolvimento do Estado e da Região do Pantanal (Uniderp); à Coordenação de Aperfeiçoamento de Pessoal de Nível Superior (Capes), pela concessão de bolsa de estudo. À gestão da APA, especificamente a Thainan Bornato; e em especial à comunidade residente na APA Baía Negra.

Marta Regina da Silva-Melo: Universidade para o Desenvolvimento do Estado e da Região do Pantanal (Uniderp), Campo Grande, MS, Brasil

E-mail: martamelors@gmail.com

Link para o currículo Lattes: http://lattes.cnpq.br/8192425520595557

Gleidson André Pereira de Melo: Universidade Federal de Mato Grosso do Sul, Campo Grande, MS, Brasil

E-mail: gandmelo@gmail.com

Link para o currículo Lattes: http://lattes.cnpq.br/1370968666001171

Neiva Maria Robaldo Guedes: Universidade para o Desenvolvimento do Estado e da Região do Pantanal (Uniderp), Campo Grande, MS, Brasil

E-mail: guedesneiva@gmail.com

Link para o currículo Lattes: http://lattes.cnpq.br/7358580565148346

Data de submissão: 04 de abril de 2019

Data de recebimento de correções: 04 de junho de 2019

Data do aceite: 04 de junho de 2019

Avaliado anonimamente 